Piotr GNATENKO ${ }^{1}$

\title{
ПРИРОДА ЧЕЛОВЕКА В КОНТЕКСТЕ ФЕНОМЕНА БЕССОЗНАТЕЛЬНОГО
}

В статье рассматривается взаимосвязь природы человека с бессознательным, роль бессознательного в структуре содержания понятия „природа человека”. Обосновывается вывод, что для анализа природы человека необходимо учитывать как биологические, так и социальные элементы его сущности.

Ключевые слова: бессознательное, сознание, стереотип, установки, природа человека.

Вопрос о том, что такое природа человека и правомерно ли употреблять данное понятие был дискуссионным в прошлом, дискуссионным он остаётся и в наше время, хотя попытки ответа на него предпринимались ещё в древнем Китае и Индии. Фундаментальную работу данной проблеме посвятил Д. Юм. Существует точка зрения о том, что никакой природы человека не существует. Данную ситуацию отразил американский учёный С. Пинкер. Он, в частности, отмечает: «В течение большей части XX века в интеллектуальной жизни Запада было широко распространённым отрицание природы человека, о чём свидетельствуют такие представительные цитаты: «у человека нет природы» - философ Ортега-и-Гассет; «у человека нет инстинктов»- антрополог и популярный интеллектуал Эшли Монтегю; «мозг человека способен обеспечивать любые формы поведения, и не предрасположен ни к одной из них» - биолог - эволюционист Джей Гоулд».

Следует отметить, что проблема природы человека является комплексной, требующей исследований со стороны философов, психологов, биологов, антропологов и представителей других наук.

Однако, как отмечает российский академик К.Л. Киселёв, существует разрыв между гуманитарными и естественными науками в познании человека, что не даёт возможности глубоко и всесторонне исследовать природу человека.

Когда Пинкера спросили, что он понимает под природой человека, Пинкер ответил: «Да, это вполне законный вопрос. Я охарактеризовал бы природу человека как совокупность эмоций, мотивов и когнитивных способностей, которые являются общими для всех индивидов с нормальной нервной системой; при этом вариации между индивидами в отношении этих свойств носят количественный, а не качественный характер».

С точки зрения Фукуямы, природа человека - это сумма поведения и типичных видов характеристик, обусловленных генетическими, а не средовыми факторами и что современная биология, в конечном счёте, даёт некоторое значимое эмпирическое содержание понятию человеческой природы. Можно приводить

${ }^{1}$ Prof. dr hab. Gnatenko Piotr Ivanovich, Katedra Filozofii Uniwersytetu Narodowego w Dniepropietrowsku, Ukraina. 
определение природы человека других авторов, однако большинство их определяют природу человека лишь через биологические её свойства.

Для объективного анализа природы человека необходимо учитывать как биологические, так и социальные факторы, которые формируют его природу.

Мир человеческих сообществ качественно отличается от мира животных, в то же время внутри человеческих сообществ, состоящих из множества индивидов, природа каждого из них отличается между собой и это отличие обуславливает, детерминирует поведение человека. Значительную роль в поведении личности и больших групп людей играет феномен бессознательного. Именно данный феномен убедительно показывает взаимосвязь биологического и социального в структуре личности.

Почему роль бессознательного в сфере межличностных отношений возрастает?

Или, возможно, она всегда была значительной? Игнорируя бессознательное в жизнедеятельности отдельного человека, наше обществоведение недооценило роли бессознательного и в сфере социальных процессов.

В концептуальном плане нет единой точки зрения на природу бессознательного. В научной литературе по данному вопросу высказываются такие три точки зрения:

1. Бессознательное - это антитезис сознания.

2. Бессознательное - это совокупность процессов, протекающих вне сознания, вне пределов его контроля.

3. Бессознательное - это один из специфических функциональных компонентов психики, по своей семантической модальности гомологичный сознанию.

Очевидно, наиболее приемлемой является третья точка зрения. В данном контексте бессознательное не рассматривается как противоположность, антитеза сознанию, а. наоборот, как категория, которая функционирует в единстве с ним.

Такое понимание бессознательного срывает с него покров мистицизма и таинственности и обеспечивает возможность его научного исследования, прежде всего, анализа поведения личности.

Этой точки зрения придерживается Л.С. Выготский, который пишет: «Бессознательное не отделено от сознания какой-то непроходимой стеной. Процессы, начинающиеся в нём, часто имеют своё продолжение в сознании, и наоборот, многое сознательное вытесняется нами в подсознательную сферу.

Существует постоянная, ни на минуту не прекращающаяся живая динамическая связь между обеими сферами нашего сознания. Бессознательное влияет на наши поступки, обнаруживается в нашем поведении, и по этим следам и проявлениям мы научаемся распознавать бессознательное и законы, управляющие им» ${ }^{2}$.

Таким образом, сознательное и бессознательное воспринимаются как два этажа единого здания. Причём бессознательное составляет нижний его этаж, а сознание верхний. Если бессознательное обусловливает решающие мотивационные функции в поведении больших масс людей, толпы, то это значит, что его роль в жизнедеятельности отдельного человека невелика. Значительная часть информации воспринимается индивидом на бессознательном уровне, и лишь ничтожная её часть становится фактом сознания.

${ }^{2}$ Бессознательное. Природа, функиии, методы исследования. Материалы международного симпозиума, Т.1, Тбилиси 1985, с.171. 
Однако в структуре личности роль бессознательного не ограничивается пассивным восприятием информации. Поведение личности, специфика её реакций на внешние воздействия не всегда объясняется внешними факторами. Существуют биологически обусловленные бессознательные мотивации. Их исследование помогает установить причины поведения индивида в самых различных ситуациях, когда ссылки на социальную детерминированность не дают исчерпывающего объяснения этого поведения.

Человек, как известно, существо биосоциальное. Это обстоятельство нужно учитывать при анализе не только структуры личности, но и особенностей национальной психологии, национального характера, т.е. тогда, когда изучаются те или иные общности людей, в том числе и национальные. В противном случае многое останется непонятным, многие явления приобретут мистическую иррациональную окраску.

Слишком долго в отечественной науке сфера бессознательного была запретной темой. В тех случаях, когда действительность не укладывалась в прокрустово ложе принятых догм, ссылались на известный тезис о том, что человек представляет собой не что иное, как продукт общественных отношений. Но жизнь в её многообразии не могут пояснить исчерпывающе никакие догмы и формулы.

Именно жизнь заставила обратиться к исследованию феномена бессознательного, который в прошлом оценивался как фрейдистский и идеалистический.

Французский психолог Л. Лебон много писал о жестокости, агрессивности толпы. Можно ли, однако, полностью объяснить этот феномен лишь ссылкой на факторы внушения, подражания, которые, как показал Лебон, существуют и активно воздействуют на поведение индивида в толпе? Не существуют ли другие, наряду с отмеченными Лебоном, причины поведения индивида в толпе и не являются ли они факторами биологического порядка, которыми манипулируют для достижения определённых целей?

В научной литературе приводятся данные о наблюдениях над животными.

Отмечается, что у животных спонтанно в определённое время проявляется агрессивность, в частности, по отношению к таким объектам, к которым в другое время они испытывали полное равнодушие. Исследования К. Лоренца, Н. Тинбергена доказали, что эти вспышки объясняются наличием у млекопитающих «центров агрессии». «У млекопитающих, в том числе у человека, в области структур лимбической системы мозга обнаружен ряд пунктов, стимуляция которых электрическим током вызывает агрессивно-оборонительное поведение, а у людей, по их самоотчётам, эмоции неприязни, враждебности, злобы. Предполагается, что эти пункты являются элементами специализированной анатомо-функциональной системы, генерирующей агрессивно-оборонительное поведение» ${ }^{3}$.

Учёные пришли к выводу, что в процессе эволюции формировалась как сама физиологическая система животных, так и на её основе агрессивный тип реакции. Он был необходим животному, ибо выполнял важнейшую оборонительную функцию в процессе внутривидовой борьбы и обеспечивал выживание более сильному. Но, сформировавшись в процессе эволюции, пункты, определяющие

\footnotetext{
${ }^{3}$ Ibidem, c. 325 .
} 
агрессивно-оборонительное поведение, во многих случаях не выполняют этой роли, т.е. они действуют и вне ситуаций опасности или конкуренции.

Видимо, существуют нейрофизиологические основания реакций агрессивности. Являясь нейрональными образованиями, эти системы должны функционировать согласно самым общим и основным законам деятельности нервных элементов вообще. Так, одним из основных свойств нейронов является их возбудимость. Механизм этой реакции заключается в том, что под влиянием поступающих к нейронам по нервным клеткам возбуждений от внешних раздражителей, нейроны разряжаются нервными импульсами, в которых отражается функция данных нервных элементов. Но и при отсутствии внешних раздражителей нейроны в результате деятельности внутриклеточных и межклеточных механизмов время от времени разряжаются спонтанно. Таким образом, импульсивная активность нейронов является неотьемлемым их свойством $u$, по всей вероятности, обязательным условием их существования ${ }^{4}$.

В случае, когда раздражители отсутствуют, нейроны физиологических систем, определяющие агрессивно-оборонительное поведение последних, испытывают сенсорное голодание, в результате чего спонтанно повышается их возбудимость ${ }^{5}$.

«У человека также существуют физиологические системы, генерирующие злобные («агрессивные») эмоции, и эти системы в соответствии с описанным нейрофизиологическим механизмом, очевидно, также способны к спонтанному возбуждению. Проявления неадекватных эмоций раздражения, злобы, гнева, ярости достаточно часто наблюдаются и хорошо известны, чтобы требовать доказательства их существования. Однако у человека отсутствуют или, по крайней мере, недостаточно эффективны присущие животным механизмы блокады агрессии (поэтому, как полагает К. Лоренц, человек от природы не является сильно выраженным хищником). Тем не менее, спонтанно возникающая у человека агрессивность проявляется отнюдь не беспорядочно, a, как мы полагаем, регулируется механизмами рационализации» ${ }^{6}$.

Известны попытки придать смысл агрессивным, злобным аффектам человека, оправдать их, обосновать их необходимостью защиты «своих» от посягательства «чужих», особенно в ситуациях межнациональных и религиозных конфликтов.

В недрах бессознательного зарождаются и формируются установки, определяющие характер поведения не только на уровне бессознательного, но и на уровнеознания. Эти установки возникают как компоненты личностной структуры. В массовом сознании они приобретают социальную окраску, за что и получили название социальных.

Исследователь данного психологического феномена Д.Н. Узнадзе пишет: «Нужно иметь в виду, что перед нами стоит вопрос об изучении не какого-нибудь психического факта, а того специфического состояния, которое я называю установкой. Для возникновения последней достаточно двух элементарных условий какой-нибудь актуальной потребности у субъекта и ситуации её удовлетворения. При наличии обох этих условий в субъекте возникает установка к определённой

\footnotetext{
${ }^{4}$ Ibidem, c. 325 .

${ }^{5}$ Ibidem, c. 326.

${ }^{6}$ Ibidem, c. 326.
} 
активности. То или иное состояние сознания, то или иное из его содержаний вырастает лишь на основе этой установки» ${ }^{7}$.

Узнадзе отмечает необходимость различать установку и возникающее на ее базе конкретное содержание, поскольку установка сама по себе не имеет ничего общего с этим содержанием, и, значит, характеризовать ее в терминах явлений сознания не допустимо. Важной особенностью концепции Узнадзе является то, что в феномене установки он видит ключ к объяснению мотиваций поведения человека.

Исходя из тезиса, что бессознательное генетически и логически предшествуют сознанию, исследователи отмечают, что установочное отражение представляет собой свойство любого живого существа. При этом установка, свойственная человеку, принципиально отличается от установки, присущей животным, поскольку в животном мире она проявляется лишь в диффузном виде. «Единственной формой существования бессознательного психического, лучше сказать - досознательного психического, является установка. Бессознательное существование установки не означает того, что она имеет следовую природу, ибо существование и суммация следа недостаточны для понимания особенности установки. В установке необходимо внутреннее участие индивида, переживание им раздражителей» ${ }^{8}$.

С точки зрения Узнадзе, установка представляет собой действительно внесознательный психический процесс. Имеются и другие точки зрения. Так, В.Ф. Басин утверждает, что существуют сознательная и бессознательная установки. Некоторые нейрофизиологи употребляют термин «физиологические установки», подразумевая под ним процессы, которые происходят в ретикулярной формации продолговатого мозга. «Воздействие среды должно привести к формированию нервных механизмов, в существовании и качестве которых заинтересованы не сами нейроны, а организм. Какие силы индивида будут приведены в готовность в каждый данный момент, какое содержание примут эти силы, это зависит от среды, т.е. объективной ситуации, необходимой организму для удовлетворения актуальной потребности»9. Опыты показали, что в формировании установок принимают участие также рецепторы. При этом определяющую роль играет тот рецептор, на который воздействует раздражитель. «Формирование установки в каждом конкретном случае начинается приведением в действие преимущественно того отдела мозга, который непосредственно получает информацию от соответствующего рецептора» ${ }^{10}$. Здесь подчёркнута физиологическая сторона механизма образования установки, без выяснения которой невозможно раскрыть содержание и природу последней.

Кроме установок, действующих на уровне отдельного индивида, существуют социальные установки, обусловленные той социальной средой, в которой живёт и осуществляет свою деятельность человек. Именно в этом контексте мы можем говорить о национальных установках, обусловленных жизнедеятельностью индивида в условиях его национального бытия.

Было бы неправильно ставить непреодолимую преграду между установками, формирующимися на основе физиологических процессов в организме человека, и

\footnotetext{
${ }^{7}$ Узнадзе Д., Психологические исследования, Москва 1966, с.15.

${ }^{8}$ Бжалава И.Т., Установка и механизмы мозга, Тбилиси 1971, с. 17.

${ }^{9}$ Ibidem, c. 20.

${ }^{10}$ Ibidem, c. 20
} 
социальными установками, обусловленными определённой социальной средой. Так же как, впрочем, неправомерно ставить между ними знак равенства. Человек, как существо биосоциальное концентрирует в себе элементы как социальной, так и биологической сущности. Таким образом, без выяснения физиологических механизмов формирования установок невозможно постичь сущности установок социальных.

В формировании понятия социальной установки большая роль принадлежит Знаниецкому и Томасу. Исследуя социально-психологические черты польского крестьянства, они показали, что анализ специфики быта, традиций, обычаев населения, оказавшегося в инородной национальной среде, не может быть проведен без анализа понятия установки. Эти учёные определяют социальную установку «как духовное состояние - отношение, выработавшееся у человека к ценностным объектам» ${ }^{11}$. При этом они указывают на двойственную природу установки, поскольку она одновременно направлена и на социальную ценность, и на личность. Специфика социальной среды создаёт предпосылки для формирования либо положительных, либо отрицательных установок.

В контексте рассматриваемого нами вопроса особенно важно постичь сущность национальных установок. Впрочем, «национальные установки» не совсем адекватно отражает особенности социальной среды и тех социальных связей, в которых пребывает личность. Правильнее говорить об установках, направленных на ценности, связанные с национальным бытием определённой общности.

Учёные выделяют такие основные типы установки: установка практического поведения; установка познания; установка социального поведения; установка реализачии психофизических сил; установка творчества ${ }^{12}$ Между некоторыми этими типами существует взаимосвязь, причём настолько тесная, что объединяет их как бы в комплекс установок. Предрасположенность личности к определённому типу установок детерминирована многими факторами, прежде всего социального характера.

Исследования Крича, Крачфильда и Балачи показали, что социальная установка не является изолированным явлением, это компонент системы установок ${ }^{13}$.

Значительный вклад в разработку проблемы бессознательного внёс Фрейд. Фрейд, создавая свою концепцию бессознательного, опирался на теоретикометодологические принципы, разработанные предшествующими философскими учениями в процессе анализа ими феномена бессознательного.

Фрейд подчёркивает, что деление психики на сознательное и бессознательное является основной предпосылкой психоанализа «и только оно даёт ему возможность понять и подвергнуть научному исследованию часто наблюдающиеся и очень важные патологические процессы в душевной жизни. Иначе говоря, психоанализ не может считать сознательное сущностью психического, но должен рассматривать сознание как качество психического, которое может присоединяться или не присоединяться к другим его качествам» ${ }^{14}$.

\footnotetext{
${ }^{11}$ Надирашвили Ш.А., Установка и деятельность, Тбилиси 1987, с.19

${ }^{12}$ Ibidem, c. 98

${ }^{13}$ Ibidem, c. 25

${ }^{14}$ Фрейд З., Я и Оно, [w:] Психология бессознательного, Москва 1990, с. 425.
} 
Фрейд отмечает, что к понятию бессознательного он пришел путём переработки опыта, в котором большую роль играла душевная динамика. По Фрейду, в психоаналитической технике нашлись средства, с помощью которых можно устранить противодействующую силу и довести соответствующие представления до сознания. «Состояние, в котором они находились до осознания, мы называем вытеснением, а сила, приведшая к вытеснению и поддерживающая его, ощущается нами во время нашей психоаналитической работы как сопротивление.

Понятие бессознательного мы, таким образом, получаем из учения о вытеснении. Вытесненное мы рассматриваем как типичный пример бессознательного» ${ }^{15}$.

Отметим, что взгляды Фрейда на проблему бессознательного изменялись на протяжении его творческой деятельности. В начале творческого пути Фрейд рассматривает бессознательное в аспекте проявления его как вытесненного или отвергнутого. Исследования феномена бессознательного в этом аспекте, как уже сказано, привело к возникновению психоанализа.

В работах, написанных в период с 1914 по 1923 год, Фрейд по-новому подходит к трактовке бессознательного. Сущность этого нового подхода состояла в том, что предметом его исследования теперь становится Я. В связи с этим Фрейд по-другому трактует понятия сознательного, предсознательного и бессознательного. Если раньше Я рассматривалось лишь как сфера проявления сознательного, то теперь Фрейд приходит к выводу о наличии в содержании Я части бессознательного. Более того, он отмечает, что бессознательное не совпадает с вытесненным, утверждая, что всё вытесненное бессознательно, но не всё бессознательное есть вытесненное.

Сложность фрейдовского понимания бессознательного состоит в многоаспектности у него данного понятия. В литературе выделены такие трактовки Фрейдом данного феномена:

- $\quad$ бессознательное как психическое проявление влечений (Оно);

- $\quad$ бессознательное как энергетический источник душевной жизни;

- бессознательное как вытесненное в течении жизни (инфантильное);

- бессознательное как особый принцип работы души (первичный процесс);

- бессознательное в смысле частей Я и Сверх-Я (Я-идеал);

- бессознательное как архаическое наследие;

- бессознательное как антоним сознания.

Сложность в трактовке бессознательного состоит также в уяснении сферы применимости бессознательного, а точнее - его реальности. Фрейд справедливо подчёркивает, что бессознательное нельзя понимать анатомически, привязывать его к каким-либо частям человеческого организма. Однако именно это утверждение послужило основанием для критики концепции бессознательного некоторыми учёными, утверждавшими, что бессознательное не существует, поскольку не может быть установлено вещественно.

Эти упрёки несправедливы, они есть проявление вульгаризаторского подхода к трактовке сложных процессов, связанных с душевной сферой человеческой жизнедеятельности.

\footnotetext{
${ }^{15}$ Ibidem, c. $426-427$.
} 
В статье «Понятие бессознательного и его значение у Фрейда» Г. Кнапп пишет, что Фрейд «считает современную науку единственно возможным путём изучения мира, однако в своё понятие бессознательного сам включает феномены, не подлежащие изучению методами точной науки» ${ }^{16}$.

С подобными упрёками (имеется ввиду вторая часть данной цитаты) согласиться нельзя. В любом случае, не все явления, особенно связанные со сферой человеческого духа, могут быть измерены методами точной науки.

Фрейд в работе «Я и Оно» даёт характеристику понятиям, которыми он оперирует: бессознательное, предсознательное и сознательное. «Мы видим, - пишет он, - что есть два вида бессознательного: латентное, но способное стать сознательным, и вытесненное, которое само по себе и без дальнейшего не может стать сознательным. Наше знакомство с психической динамикой не может оказать влияния на номенклатуру и описание. Латентное бессознательное, являющееся бессознательным только в описательном, но не в динамическом смысле, называется нами предсознательным; термин «бессознательное» мы применяем только к вытесненному динамическому бессознательному: таким образом, мы имеем теперь три термина: «сознательное», «предсознательное» и «бессознательное», смысл которых уже не только чисто описательный. Предсознательное предполагается нами стоящим гораздо ближе к сознательному, чем бессознательное, а так как бессознательное мы называли психическим, мы тем более назовём так и латентное предсознательное» ${ }^{17}$.

Фрейд отмечает, что установление факта включения в содержание Я бессознательного ещё не достаточно для раскрытия сущностного содержания Я. Ситуация усложняется ещё и многокачественностью и многозначностью бессознательного. Рассматривая в концептуальном плане бессознательное, Фрейд отмечает, что бессознательное мы можем постичь только превращением его в сознательное. Как это происходит? Фрейд считает, что сознание представляет собой поверхностный слой душевного аппарата, то есть функцию некоей системы, пространственно наиболее близкой к внешнему миру. При этом Фрейд понимает пространственно не только как функцию, но и как анатомическое расчленение. Он считает, что сознательными являются все восприятия, приходящие извне (чувственные восприя-тия), а также изнутри (ощущения и чувства). Но в связи с этим возникает вопрос, как толковать внутренние процессы, которые Фрейд называет мыслительными. Эти процессы происходят где-то внутри аппарата как движения внутренней энергии на пути к действию, в силу которого возникает сознание. «Или, наоборот, сознание доходит до них? Мы замечаем, что здесь кроется одна из трудностей, встающих перед нами, если мы хотим всерьёз оперировать с пространственным, топическим представлением душевной жизни» ${ }^{18}$.

В концепции психоанализа Фрейда значительное место занимает его учение о психическом, или душевном, аппарате.

\footnotetext{
16 Кнапп Г., Понятие бессознательного и его значение у Фрейда, [w:] Энциклопедия глубинной психологии, Т.1, Москва 1998, с. 285

${ }^{17}$ Фрейд З., Я и Оно, [w:] Психология бессознательного, Москва 1990, с. 427.

${ }^{18}$ Ibidem, c. 429.
} 
Фрейд считает, что при рождении человека психический аппарат только лишь начинает формироваться, его становление и структурирование происходят в процессе развития личности. На первом периоде своего творчества он не придавал внутренним силам (внутренним потребностям и внутреннему психическому давлению) большого значения в аспекте их влияния на психический аппарат. Но в конце этого периода он пересмотрел свою точку зрения по данному вопросу и стал придавать внутренним силам большее значение.

\section{ЛИТЕРАТУРА}

[1] Бессознательное. Природа, функичи, методы исследования. Материалы международного симпозиума, Т.1, Тбилиси 1985.

[2] Бжалава И.Т., Установка и механизмы мозга, Тбилиси 1971.

[3] История философии, [w:] Энциклопедия, Минск 2002.

[4] Кнапп Г., Понятие бессознательного и его значение у Фрейда, [w:] Энциклопедия глубинной психологии, Т.1, Москва 1998.

[5] Надирашвили Ш.А., Установка и деятельность, Тбилиси 1987.

[6] Узнадзе Д., Психологические исследования, Москва 1966.

[7] Фрейд 3., Я и Оно, [w:] Психология бессознательного, Москва 1990.

\section{NATURA LUDZKA W KONTEKŚCIE FENOMENU NIEŚWIADOMOŚCI}

W artykule przeanalizowano związek natury ludzkiej z nieświadomością, rolę nieświadomości w strukturze treści pojęcia „natura ludzka”. Uzasadnia się wniosek, że w analizie natury ludzkiej powinno uwzględniać zarówno biologiczne jak i społeczne elementy istoty człowieka.

Słowa kluczowe: nieświadomość, świadomość, stereotyp, nastawienia, natura człowieka.

\section{THE NATURE OF HUMAN BEING IN THE CONTEXT OF THE PHENOMENON OF THE UNCONSCIOUSNESS}

The article examines the relationship of human nature with the unconscious, the role of the unconscious in the structure of the content of the concept of "human nature". It justifies the conclusion that for the analysis of human nature one needs to take into account both biological and social elements of their nature.

Keywords: unconscious mind, stereotype, directions, the nature of man.

DOI:10.7862/rz.2012.einh.24 